\title{
Preparation of organic polymer flocculant and its application in drilling fluid
}

\author{
Ya Shi ${ }^{1}$, Wenyu $\mathrm{Ji}^{2}$, Xiwen Jia ${ }^{3}$, Le Qu ${ }^{4}$, Jie Zhang ${ }^{1}$, Rui Zhou ${ }^{1}$, Chen Gang ${ }^{1}$, Yongfei Li ${ }^{1}$ \\ ${ }^{1}$ Shaanxi Province Key Laboratory of Environmental Pollution Control and Reservoir Protection Technology of Oilfields, Xi'an Shiyou \\ University, Xi'an, 710065, China \\ ${ }^{2}$ Xi' an Changqing Chemical Group Co. Ltd, Xi'an Shaanxi, 710068, China \\ ${ }^{3}$ Oil Production No.8, Changqing Oilfield Company, CNPC, Xi'an, 710000, China \\ ${ }^{4}$ Xi' an Key Laboratory of Tight oil (Shale oil) Development, Xi'an Shiyou University, Xi'an, 710065, China
}

\begin{abstract}
A flocculant (DES0-0) was synthesized by epichlorohydrin and diethylamine, followed by adding crosslinking agent such as ethylenediamine, diethylenetriamine and triethylenetriamine to obtain the crosslinked polymer DES0-1, DES0-2, DES0-3. The flocculation effect of DES0-1, DES0-2, DES0-3 and PAM was studied by measuring the volume, transmittance and particle size of the clarified solution after flocculation. The results showed that the flocculation effect of triethylenetetramine crosslinked polymer (DES0-3) and PAM was better. Meanwhile, the flocculation effect was more optimistic in the strong alkali environment.
\end{abstract}

Key words: Epichlorohydrin; Diethylamine; Flocculant; Crosslinking agent.

\section{Introduction}

Drilling fluid was often used in modern oil and gas well drilling operations. In drilling operations, drilling fluids provided a series of important functions, such as preventing formation fluids from entering the wellbore, removing drill cuttings, suspending drill cuttings during drilling pauses, and keeping the drill bit cool and clean[15]. Due to the rapid development of the petroleum industry, the composition of drilling wastewater had become more and more diversified in recent years. At present, the harmless treatment of drilling fluid waste is only carried out from physical, chemical, biological and other aspects that including coagulation, adsorption, reverse osmosis, chemical oxidation and electrolysis, and biological treatment. It has been widely used in drilling wastewater treatment[6,7]. In conventional operations, drillingfluids were always recirculated by removing useless solid pollutants because they were costly and hazardous if directly discharged to the environment [8-10]. However, due to solid contaminants will increase the viscosity and friction of the drilling fluid, reduce the rate of penetration (ROP), and thereby reduce the performance of the drilling fluid, the most important task of drilling fluid recycling is to remove the useless solid phase in the return fluid[11]. Flocculation is an effective and economical method to treat water and wastewater[12,13]. Natural and synthetic polymers can make colloidal suspensions unstable and have been found to be widely used as flocculants [14]. Water-soluble synthetic polymers have the disadvantages of non-biodegradability and high cost. Therefore, there is an increasing demand for efficient, inexpensive, and environmentally friendly flocculants for water and wastewater treatment. ndustrial flocculants are sometimes not suitable for oilfields due to their poor water solubility, small molecular weight, low charge density, and high concentration[15]. Polyamines are quaternary ammonium cationic polymers that have been used as flocculants and charge neutralizers in the pulp and mining industries. A number of studies have found that polyamines are effective in a wide $\mathrm{pH}$ range are easy to handle and immediately dissolve in aqueous systems[16,17]. Moreover, the cationic polymer neutralizes the charge by compressing the electric double layer, adsorbs and then forms a bridge, and the removal rate is high[18,19]. In this paper, ethylenediamine and epichlorohydrin with two-step polymerize to polyamine (DES0-0), using ethylenediamine, diethylenetriamine and triethylenetetramine as crosslinking agents to synthesize crosslinked polymer DES0-1, DES0-2, DES0-3 mix with PAM. After flocculation, the flocculation was evaluated by measuring in these aspects which and the particle size diameter of the floc and the volume of the supernatant and the light transmittance. 


\section{Materials and methods}

\subsection{Materials}

Rereagents involved in the experiment, such as epichlorohydrin, diethylamine, ethylenediamine, diethylenetriamine and triethylenetetramine (analytical purity), were purchased from Chengdu Kelong Chemical Reagent Factory. Polyacrylamide (molecular weight is more than or equal to 3 million) were provided by Shanghai Shanpu Chemical Co., Ltd.

\subsection{Preparation of polyamine salt and flocculant}

Adding sodium oleate and epichlorohydrin with a molar ratio of $1: 1$ in a round-bottom flask, $1 \%$ potassium iodide was used as a catalyst and ethanol was used as a solvent under refluxing for $2 \mathrm{~h}$ to obtain product 1 . In another round bottom flask, epichlorohydrin and diethylamine with a molar ratio of 1:1 was added based on ethanol as the solvent, and then transfered product 1 into this flask, continued to reflux for $2 \mathrm{~h}$ to evaporate the solvent ethanol to obtain the final product. After dripping, the mixture was heated at $80^{\circ} \mathrm{C}$ and keept the reaction for $240 \mathrm{~min}$ to obtain the polyamine.

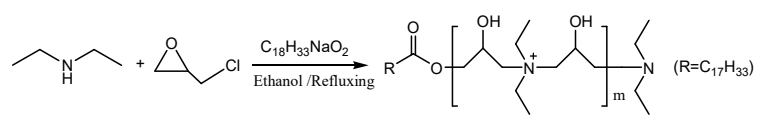

Figure 1 Synthesis mechanism

\subsection{Crosslinking reaction}

After adding the resulting polyamine salt medicine, a certain proportion of cross-linking agent was added. The reaction was carried out for $5 \mathrm{~h}$ kept with $60^{\circ} \mathrm{C}$ until there was no pungent odor in the reactant to obtain the DES0-1, DES0-2, DES0-3.

\subsection{Synthetic viscosity measurement}

The viscosity of the polymer was measured using a 0.8 $0.9 \mathrm{~mm}$ ubbelohde viscometer. The time of synthetic stream passing through capillary tube was measured at room temperature, followed by the corresponding kinematic viscosity was converted into standard viscosity according to formula.

\subsection{Laser particle size determination method}

Flocculant was added to the drilling fluid base slurry for flocculation, then transfered an appropriate amount of suspension to measure the particle size and distribution of flocs with laser diffraction particle size analyzer.

\subsection{Base slurry configuration}

The $4 \%$ bentonite was added to a certain amount of water under stirring with certain speed for $2 \mathrm{~h}$, followed by age for $24 \mathrm{~h}$.

\subsection{Flocculation performance measurement}

After the flocculation by adding flocculant to drilling fluid base slurry, an appropriate amount of suspension was transfered, followed by centrifugation. The volume of the supernatant was measured and the light transmittance was measured with a visible spectrophotometer.

\subsection{Characterization of flocculants}

A certain amount of synthetic products were analyzed by Fourier infrared spectrometer. The mixture consisting of sample and potassium bromide with a ratio of 1:100 (mass ratio) was put in mold, followed by tablet compressing.

\section{Results and discussion}

\subsection{Optimization of flocculant synthesis conditions}

\subsubsection{Screening of reactant molar ratio}

Table 1 and Figure 2 reflected the viscosity of the synthesized compound under different molar ratios. It suggested that when the molar ratio of epichlorohydrin to diethylamine was $1.5: 1$, the kinematic viscosity and dynamic viscosity of the compound reach the maximum, implying that the molecular weight of the composite is the largest. The larger the molecular weight, the better the flocculation effect. Therefore, the molar ratio of reactants is $1.5: 1$.

Table 1 Compound related data in different molar ratios

\begin{tabular}{ccc}
\hline $\begin{array}{c}\text { The molar } \\
\text { ratio }\end{array}$ & $\begin{array}{c}\text { Kinematic } \\
\text { viscosity } \mathrm{m}^{2} / \mathrm{s}\end{array}$ & $\begin{array}{c}\text { Dynamic viscosity } \\
/ \text { mpa.s }\end{array}$ \\
\hline $1: 1$ & 1.800 & 2.03 \\
$1: 2$ & 2.590 & 2.94 \\
$1: 1.5$ & 5.025 & 9.52 \\
$1.5: 1$ & 12.750 & 15.58 \\
$2: 1$ & 10.800 & 13.50 \\
\hline
\end{tabular}

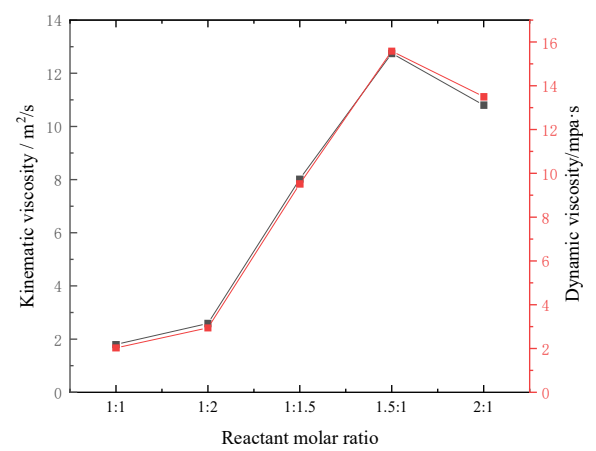

Figure 2 The influence of reactant molar ratio on product viscosity 


\subsubsection{Screening of measurement standard for crosslinking agent}

Table 2 and Figure 3 showed that the relevant data of the product after crosslinking with a $3 \%$ crosslinking agent and a reactant with a molar ratio of $1.5: 1$. It illustrated that the composition containing triethylenetetramine had the highest viscosity. However, epichlorohydrin and amines were used to synthesize polymers under the condition of a certain amount of crosslinking agent, the greater of the cationicity which the smaller the amine group contained in the crosslinking agent structure. The flocculation had a great relationship with the content of cations, so ethylenediamine was selected as the content determination standard.

Table 2 Data related to the composition with different crosslinking agents

\begin{tabular}{ccc}
\hline $\begin{array}{c}\text { Type of crosslinking } \\
\text { agent }\end{array}$ & $\begin{array}{c}\text { Kinematic } \\
\text { viscositym }{ }^{2} / \mathrm{s}\end{array}$ & $\begin{array}{c}\text { Dynamic } \\
\text { viscosity } \\
/ \mathrm{mpa} \cdot \mathrm{s}\end{array}$ \\
\hline $\begin{array}{c}\text { Ethylenediamine } \\
\text { Diethylenetriamine }\end{array}$ & 10.76 & 13.00 \\
Triethylenetetramine & 12.26 & 15.23 \\
\hline
\end{tabular}

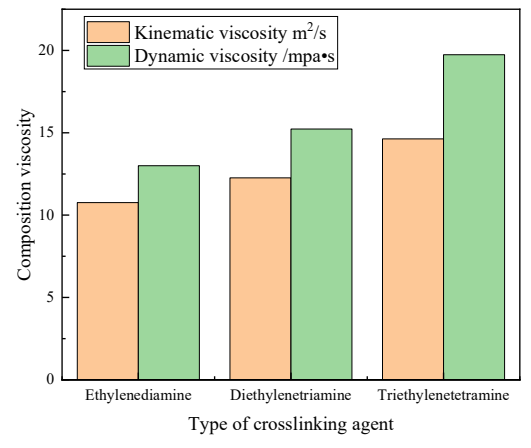

Figure 3 The effect of crosslinking agent on polymer viscosity

\subsubsection{Determination of the dosage of crosslinker}

Dethylamine crosslinking with reactants which the molar ratio was 1.5:1 were seleced to explore the influence of the content of the cross-linking agent on the viscosity of the synthetic products. A blank which added a certain amount of distilled wate was set during the measurement, and then set five different dosages of $0 \%, 1 \%, 2 \%, 3 \%, 4 \%$ to determine the optimum dosage of crosslinking agent. It can be seen intuitively from Table 3 and Figure 4 that the viscosity of the composition containing $4 \%$ of the crosslinking agent was relatively large, and the viscosity of the $3 \%$ and $4 \%$ organic polymer composition was not very different. Comparing with the cationicity,due to it was found that $3 \%$ of the polymer had a higher cationicity, a polymer with a content of $3 \%$ was selected.
Table 3 Data related to the composition with different content of cross-linking agent

\begin{tabular}{ccc}
\hline $\begin{array}{c}\text { Crosslinking } \\
\text { agent content }\end{array}$ & $\begin{array}{c}\text { Kinematic } \\
\text { viscositym }{ }^{2} / \mathrm{s}\end{array}$ & $\begin{array}{c}\text { Dynamic } \\
\text { viscosity } \\
\text { /mpa.s }\end{array}$ \\
\hline $0 \%$ & 6.30 & 7.70 \\
$1 \%$ & 7.01 & 8.47 \\
$2 \%$ & 8.36 & 9.78 \\
$3 \%$ & 10.99 & 13.23 \\
$4 \%$ & 12.64 & 15.29 \\
\hline
\end{tabular}

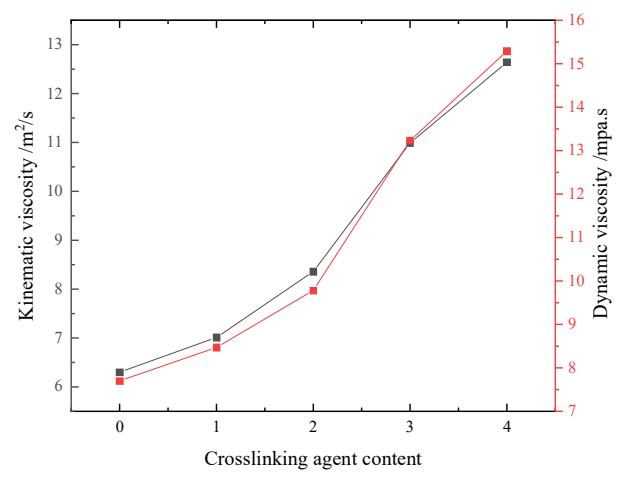

Figure 4 The influence of crosslinking agent content on polymer viscosity

\subsection{Evaluation of flocculation effect of flocculant and PAM}

The mixture which had different concentrations of flocculant and 70ppm PAM was added to the drilling fluid base slurry. The flocculation effect on the drilling fluid base slurry was investigated by analyzing the volume and permeability of the centrifugal liquid and the particle size diameter of the flocs. The experimental results were followed.

Table 4 DES0-0 and PAM compound flocculation effect

\begin{tabular}{ccccccc}
\hline DES0-0 & 0 & $\begin{array}{c}0.10 \\
\%\end{array}$ & $\begin{array}{c}0.15 \\
\%\end{array}$ & $\begin{array}{c}0.20 \\
\%\end{array}$ & $\begin{array}{c}0.25 \\
\%\end{array}$ & $\begin{array}{c}0.30 \\
\%\end{array}$ \\
\hline $\begin{array}{c}\text { Volume of } \\
\text { supernatant/ } \\
\mathrm{mL}\end{array}$ & $\begin{array}{c}152 . \\
0\end{array}$ & 152.0 & 150.0 & 153.0 & 157.0 & 157.0 \\
$\begin{array}{c}\text { Transmittanc } \\
\mathrm{e} / \%\end{array}$ & 99.5 & 79.4 & 90.0 & 96.4 & 99.0 & 100.0 \\
$\begin{array}{c}\text { Particle size } \\
\text { diameter } / \mu \mathrm{m}\end{array}$ & 503. & 144.6 & 148.2 & 150.5 & 152.5 & 281.0 \\
\hline
\end{tabular}

Table 5 DES0-1 and PAM compound flocculation effect

\begin{tabular}{cccccc}
\hline DES0-1 & 0 & $0.4 \%$ & $0.5 \%$ & $0.6 \%$ & $0.7 \%$ \\
\hline $\begin{array}{c}\text { Volume of } \\
\text { supernatant } / \mathrm{mL}\end{array}$ & 151.8 & 130.2 & 128 & 140 & 139.8 \\
Transmittance $/ \%$ & 98.8 & 81.8 & 85.3 & 91.6 & 98.1 \\
$\begin{array}{c}\text { Particle size } \\
\text { diameter } / \mu \mathrm{m}\end{array}$ & 463.5 & 151.3 & 153.2 & 154.6 & 189.7 \\
\hline
\end{tabular}


Table 6 DES0-2 and PAM compound flocculation effect

\begin{tabular}{cccccc}
\hline DES0-2 & 0 & $0.4 \%$ & $0.5 \%$ & $0.6 \%$ & $0.7 \%$ \\
\hline $\begin{array}{c}\text { Volume of } \\
\text { supernatant } / \mathrm{mL}\end{array}$ & 151.8 & 145 & 157 & 148 & 151 \\
$\begin{array}{c}\text { Transmittance } / \% \\
\text { Particle size }\end{array}$ & 98.8 & 94.2 & 94.3 & 96.7 & 95.9 \\
diameter $/ \mu \mathrm{m}$ & 463.5 & 147.5 & 151.7 & 158.5 & 169.7 \\
\hline
\end{tabular}

Table 7 DES0-3 and PAM compound flocculation effect

\begin{tabular}{cccccc}
\hline DES0-3 & 0 & $0.10 \%$ & $0.2 \%$ & $0.25 \%$ & $0.30 \%$ \\
\hline $\begin{array}{c}\text { Volume of } \\
\text { supernatant } / \mathrm{mL}\end{array}$ & 153 & 126.1 & 137.2 & 145.1 & 146.5 \\
$\begin{array}{c}\text { Transmittance } / \% \\
\text { Particle size }\end{array}$ & 98.5 & 90.8 & 90.9 & 95.1 & 98.9 \\
diameter $/ \mu \mathrm{m}$ & 489.1 & 147.5 & 150.6 & 153.8 & 156.5 \\
\hline
\end{tabular}

With the continuous increase of the mass fraction of flocculant was added into the drilling fluid, the high molecular chain will have the effect of net capture and adsorption bridging on the bentonite. Meanwhile, due to the rich positive charge contained on it will neutralize the negative charge on the end face of the bentonite, which will have the effect of pulling and sinking the solid suspension and the transmittance and the particle size diameter of flocs are also increasing. The DES0-3 had a better effect with PAM.

\subsection{Flocculation effect of flocculant in different $\mathrm{pH}$ environment}

The $\mathrm{pH}$ value of the drilling fluid base slurry was adjusted by hydrochloric acid and sodium hydroxide. The experimental results of the flocculation effect on the drilling fluid base slurry at different $\mathrm{pH}$ were investigated by analyzing the volume and permeability of the centrifuged liquid and the particle size diameter of the flocs. The experimental results were followed.

Table 8 Flocculation effect of DES0-0 under different $\mathrm{pH}$ conditions

\begin{tabular}{cccccc}
\hline $\mathrm{pH}$ & 4 & 5 & 6 & 7 & 8 \\
\hline Volume of & 173.0 & 177.0 & 175.0 & 160.0 & 160.0 \\
supernatant/mL & & & & \\
Transmittance $/ \%$ & 99.4 & 100.0 & 99.5 & 99.0 & 99.0 \\
$\begin{array}{c}\text { Particle size diameter } \\
/ \mu \mathrm{m}\end{array}$ & 114.4 & 125.3 & 112.6 & 106.1 & 183.2 \\
\hline
\end{tabular}

Table 9 Flocculation effect of DES0-1 under different $\mathrm{pH}$ conditions

\begin{tabular}{cccccc}
\hline $\mathrm{pH}$ & 4 & 6 & 7 & 9 & 11 \\
\hline $\begin{array}{c}\text { Volume of } \\
\text { supernatant } / \mathrm{mL}\end{array}$ & 145.1 & 146.1 & 134.2 & 134.0 & 143.0 \\
$\begin{array}{c}\text { Transmittance } / \% \\
\begin{array}{c}\text { Particle size } \\
\text { diameter } / \mu \mathrm{m}\end{array}\end{array}$ & 97.4 & 99.9 & 86.9 & 94.1 & 91.8 \\
\hline
\end{tabular}

Table 10 Flocculation effect of DES0-1 under different $\mathrm{pH}$ conditions

\begin{tabular}{cccccc}
\hline $\mathrm{pH}$ & 4 & 6 & 7 & 9 & 11 \\
\hline $\begin{array}{c}\text { Volume of } \\
\text { supernatant } / \mathrm{mL}\end{array}$ & 170.0 & 171.1 & 172.5 & 160.3 & 168.6 \\
$\begin{array}{c}\text { Transmittance } / \% \\
\text { Particle size diameter } \\
/ \mu \mathrm{m}\end{array}$ & 98.8 & 99.9 & 99.9 & 88.8 & 95.1 \\
$\begin{array}{c}\text { Tam } \\
\text { (153.3 }\end{array}$ & 196.4 & 191.3 & 156.3 & 163.2 \\
\hline
\end{tabular}

Table 11 Flocculation effect of DES0-1 under different $\mathrm{pH}$ conditions

\begin{tabular}{cccccc}
\hline $\mathrm{pH}$ & 4 & 6 & 7 & 9 & 11 \\
\hline Volume of & 155.1 & 152.0 & 152.2 & 151.1 & 159.5 \\
supernatant $/ \mathrm{mL}$ & 87.2 & 96.8 & 97.5 & 93.6 & 97.5 \\
$\begin{array}{c}\text { Transmittance } / \% \\
\text { Particle size diameter } \\
/ \mu \mathrm{m}\end{array}$ & 110.3 & 92.5 & 93.1 & 112.5 & 176.4 \\
\hline
\end{tabular}

It can be seen from table 8,9,10,11 that the flocculation effect of the DES0-1, DES0-2 and PAM is the best when $\mathrm{pH}$ is 6 , while the flocculation effect of the products synthesized with DES0-3 and PAM is the best when $\mathrm{pH}$ is 11. This is because the crosslinked products of diethylamine and triethylenetetramine as crosslinking agents can dissociate more cations which enhance the electrostatic attraction under alkaline conditions, so that the adsorption performance is improved, and the flocculation effect is also improved. However, due to the total negative charge of the bentonite particles itself is small, the total negative charge of the base slurry itself is small cause to the adsorption capacity for cations is small. When the $\mathrm{pH}$ was too high, the cations dissociated from the flocculant will appear to be excessive. On the contrary, the particles will be repelled due to the positive charge, which is not conducive to agglomeration.

\subsubsection{Infrared analysis}

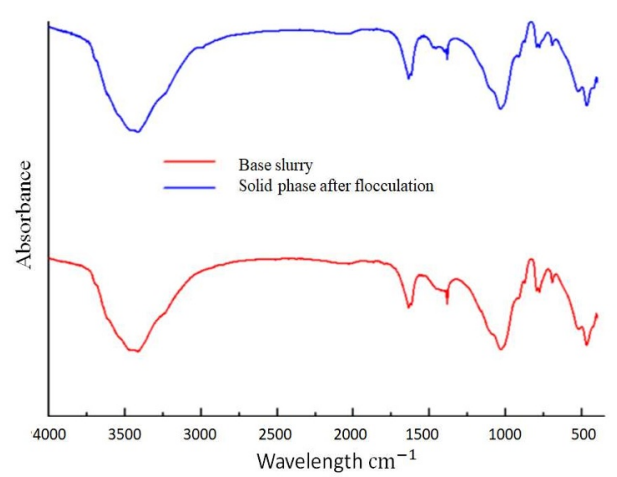

(a) DES0-0 


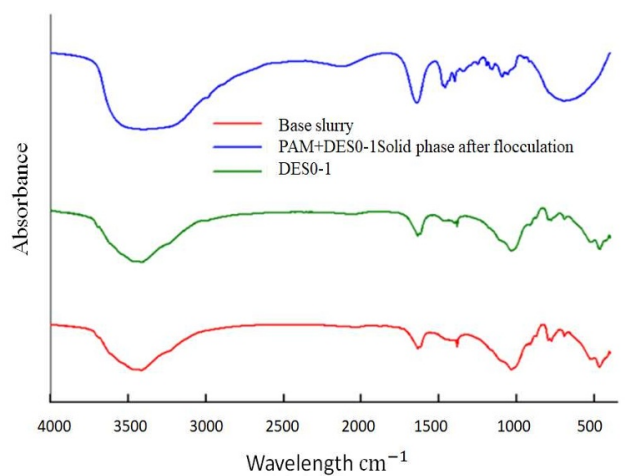

(b) DES0-1

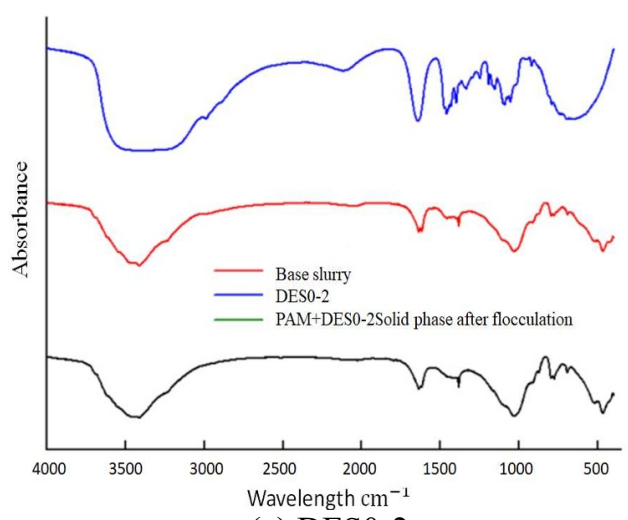

(c) DES0-2

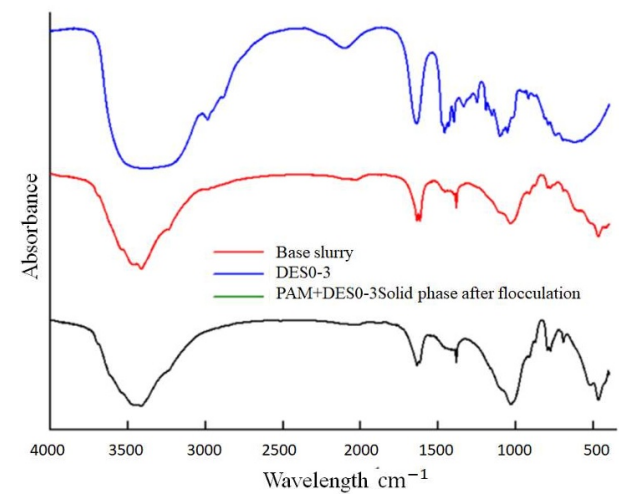

(d) DES0-3

Figure 5 FTIR spectra of polymer

It can be concluded from the above infrared spectra that the special peak shape of the ternary epoxy in the molecular structure of epichlorohydrin had disappeared. $978 \mathrm{~cm}^{-1}$ was the characteristic absorption peak in the molecular structure of quaternary ammonium salt. A series of sharp peaks from $2800 \mathrm{~cm}^{-1}$ to $3050 \mathrm{~cm}^{-1}$ were the stretching vibration peaks of methyl $\mathrm{CH}_{3}$ - and methylene $\mathrm{CH}_{2}$-, which indicates that cationic quaternary ammonium salt had been formed. The absorption peak of water molecular structure appeared at about $3300 \mathrm{~cm}^{-1}$. Compared with the infrared characteristic peaks of the base slurry and flocculant, the main characteristic absorption peaks of the base slurry and flocculant were shown in the infrared spectrum of the solid phase after flocculation and indicating that the flocculant had been adsorbed on the base slurry and played the role of adsorption flocculation.

\section{Conclusions}

In this paper, a series of crosslinked polymer such as DES0-1, DES0-2, DES0-3, was synthesized via adding ethylenediamine, diethylenetriamine and triethylenetriamine to a flocculant (DES0-0) obtained by epichlorohydrin and diethylamine, followed by flocculation evaluation. The results suggested that the relative molecular mass of triethylenetetramine (DES0-3) was higher than ethylenediamine (DES0-1) and diethylenetriamine (DES0-2). The polymer chain had a great effect on the net capture, adsorption and bridging of bentonite, and a pull-sinking effect on suspended solids. Meanwhile, it was found that the cross-linked product of triethylenetetramine as a cross-linking agent will not dissociate too many cations. The excess cations would cause the particles to be positively charged and charge repulsion, which is not conducive to agglomeration. Therefore, the triethylenetetramine cross-linked polymer can achieve better results when it is compounded with PAM under alkaline conditions.

\section{Acknowledgments}

The work was supported financially by Shaanxi Provincial Key Research and Development Program (2019GY-136), Key Scientific Research Program of Shaanxi Provincial Department of Education (21JY035) and Youth Innovation Team of Shaanxi University. And we thank the work of Modern Analysis and Testing Center of Xi`an Shiyou University.

\section{References}

1. Fink J. Petroleum engineer's guide to oil field chemicals and fluids (Second Edition) [M]. 2015.

2. Hart PJ, Snyder RK. Method for on-site treatment of oil and gas well waste fluids: US, US7022240 B2[P]. 2006.

3. Landis CR, Collins RP, Anderson EA, et al. Novel injection flocculation and compression dewatering unit for solids control and management of drilling fluids and methods relating thereto: US, US20130015141 A1[P]. 2013.

4. Nagham Amer Sami. Effect of magnesium salt contamination on the behavior of drilling fluids[J]. Egyptian Journal of Petroleum,2016, 25(4): 453-458.

5. Ball AS, Stewart RJ, Schliephake K. A review of the current options for the treatment and safe disposal of drill cuttings[J].Waste Manag Res, 2012, 30(5): 457473.

6. Wang Y, Wang T, Yan X. Discussion on harmless treatment technologies of drilling fluid waste in oil and gas fields[J]. IOP Conference Series Earth and Environmental Science, 2020, 446: 052037. 
7. Wang JP, Chen YZ, Ge XW, et al. Gamma radiationinduced grafting of a cationic monomer onto chitosan as a flocculant[J]. Chemosphere, 2007, 66(9): 17521757.

8. Jiang G, Peng S, Li X, et al. Preparation of amphoteric starch-based flocculants by reactive extrusion for removing useless solids from waterbased drilling fluids[J]. Colloids \& Surfaces A Physicochemical \& Engineering Aspects, 2018, 558: 343-350.

9. Elnenay AEMH, Nassef E, Malash GF, et al. Treatment of drilling fluids wastewater by electrocoagulation[J]. Egyptian Journal of Petroleum, 2016, 26(1): 203-208.

10. Hamed SB, Belhadri M. Rheological properties of biopolymers drilling fluids[J]. Journal of Petroleum Science \& Engineering, 2009, 67(3-4): 84-90.

11. Peng, Shuanglei, Jiang, et al. Flocculation of submicron particles in water-based drilling fluids by CMC-g-DMDAAC[J]. Journal of Petroleum Science \& Engineering, 2018, 162: 55-62.

12. Yang WY, Qian JW, Shen ZQ. A novel flocculant of $\mathrm{Al}(\mathrm{OH}) 3$-polyacrylamide ionic hybrid[J]. Journal of Colloid \& Interface Science, 2004, 273(2):400-405.

13. Tripathy T, Singh RP. High performance flocculating agent based on partially hydrolysed sodium alginateg-polyacrylamide[J]. European Polymer Journal, 2000, 36(7): 1471-1476.

14. Aly AA. Preparation and evaluation of some anionic starch derivatives as flocculants[J]. Starch-Strke, 2010, 58(8): 391-400.

15. Jing Z, Hong Z, Wang F, et al. Preparation of a new inorganic-organic composite flocculant used in solid-liquid separation for waste drilling fluid[J]. Chemical Engineering Journal, 2011, 171(1): 350356.

16. Joo DJ, Shin WS, Kim YH, et al. Effect of polyamine flocculant types on dye wastewater $\mathrm{t}$ reatment. Separation Science and Technology,2003, 38(3), 661-678.

17. Yue QY, Gao BY, Wang Y, et al. Synthesis of polyamine flocculants and their potential use in treating dye wastewater[J]. Journal of Hazardous Materials, 2008, 152(1): 221-227.

18. L Besra and D.K Sengupta and S.K Roy and P Ay. Polymer adsorption: its correlation with flocculation and dewatering of kaolin suspension in the presence and absence of surfactants[J]. International Journal of Mineral Processing, 2002, 66(1-4): 183-202.

19. Avci D, Mol N, Dagasan L. New cationic polyelectrolytes for flocculation processes of baker's yeast waste water[J]. Polymer Bulletin, 2002, 48(45): 353-359. 